\title{
Relationship Between Palatally Impacted Canines and Sella Turcica Bridging
}

Omair Majeed ${ }^{1}$

Tabassum Ahsan Quadeer ${ }^{2}$

Maria Habib $^{3}$
BDS

BDS, FCPS

BDS

OBJECTIVE: To investigate the association between palatal canines and sella bridging as well as to establish the type of calcification of sella common to subjects with impacted canines.

METHODOLOGY: The sample included male and female patients aged above 12 years, presenting to the orthodontic OPD of Bahria University Medical and Dental College for fixed or removable orthodontic treatment the sample was 105 divided into subjects (34) and control (71) groups. The control group included patients having normally erupted canines while subjects included at least one palatally impacted canine. The presence of impacted canines was confirmed on OPG while sellae dimensions were measured on lateral cephalometric radiographs. Data was analyzed and factors such as sella dimensions (length, depth and diameter) as well as degree of calcification and its relation to presence of palatally impacted canines was determined by using Chi square test, independent sample $t$ test as well as Pearson correlation test. RESULTS: The mean interclinoidal distance and sella diameter was reduced in subjects as compared to controls. Type II calcification was dominant in both experimental (76.5) and control (78.9) groups. There was a significant negative correlation found amongst subjects and controls using Pearson correlation. The strength of association was higher among subjects as compared to control group.

CONCLUSION: Sella bridging is an indicator of palatal impaction of canines as the length and diameter of sella were reduced in experimental subjects. Type II calcification was dominant in subjects as well as control groups. KEY WORDS: Sella Turcica Palatal impactions.

HOW TO CITE: Majeed O, Quadeer TA, Habib M. Relationship between palatally impacted canines and sella turcica bridging. J Pak Dent Assoc 2018;27(4):160-64.

DOI: https://doi.org/10.25301/JPDA.274.160

Received: 24 July 2018, Accepted: 28 August 2018

\section{INTRODUCTION}

$\mathrm{D}$ ental anomalies are a common occurrence in different populations and can comprise of missing teeth, supernumeraries, ectopic eruptions, palatal canine impactions, distal or mesial tipping along with changes in sizes and shapes. Multiple studies have been conducted to find the associations between different anomalies, as they help in diagnosing subsequent occurrences.

Lateral cephalometric radiographs are of vital importance in the field of Orthodontics. They aid in diagnosis, formulation of treatment plans as well as in assessing the results at the

1. Senior Lecturer, Department of Orthodontics, Bahria university Medical and Dental College, Karachi, Pakistan.

2. Associate Professor, Department of Orthodontics, Bahria university Medical and Dental College, Karachi, Pakistan.

3. Senior Lecturer, Department of Orthodontics, Bahria university Medical and Dental College, Karachi, Pakistan.

Corresponding author: "Dr. Omair Majeed" < dromairis@hotmail.com > end of the treatment. Dental anomalies are generally not isolated occurrences, and there are invariably relationships between them and some anatomical occurrences ${ }^{1}$, which might be chance findings in the regular records.

Sella turcica is a bony structure found anatomically in the sphenoid bone and belongs to the middle cranial fossa. Its deepest part is the hypophyseal fossa where the pituitary gland is located. It is named because of its resemblance to a saddle, having supports in the front and the back. It is a structure that can be easily visualized on a lateral cephalometric radiograph. Its shape and structure can be traced for various analyses in orthodontic treatment planning, assessing craniofacial morphology, and is also routinely used for superimpositions during growth studies. Sella has been divided into three segments having anterior, posterior walls and a floor, while morphologically its shape can be flat or oval. $^{2}$

Research has been done on the radiographic anatomy 
and morphological variations of sella, so that any deviation from the normal can be recognized. Studies have also been conducted to relate the morphologic variations with different dental anomalies or malocclusions, which can help in the early diagnosis of such cases. ${ }^{3}$ Anatomically the anterior border of sella is called tuberculum sellae while the posterior border is called dorsum sellae. The anterior clinoid process is formed by the anterior and medial projections of the lesser wing of the sphenoid bone while the posterior clinoid process is formed by endings of dorsum sella. ${ }^{4}$ Interclinoid ligament calcification of sella turcica is called sella bridging, and has been linked with anomalies and aberrations in the craniofacial structure, along with variations of eruptions, impactions and missing teeth to name a few. The etiology of this bridging is however unclear though there are some evidences of an underlying genetic connection. As there is genetic evidence for both, the bridging and various dental anomalies, studies have been carried out showing its presence whenever dental anomaly or anatomical variations exist. Other studies have shown a prevalence of the bridging in normal population as well and found it to be between $1.1 \%$ to $22 \% .^{5,6}$

The prevalence of this bridging varies in different populations, and locally we could find scarce data on this subject being done on Pakistani population that compared the bridging difference in normal cases and those with palatal impacted canines. ${ }^{7}$ Our study aims to add to the local studies is our population and also to find if there is any difference in the bridging between palatal canines and normal cases in males and females.

\section{METHODOLOGY}

The study was cross sectional and was carried out in the Orthodontic Department at Bahria University Medical and Dental College. The sample size was 105 and calculated using the study of Ali B, ${ }^{8}$ and was estimated using power of $80 \%$ and confidence interval of $95 \%$.

Records of the patients coming to the Orthodontic OPD at BUMDC who had palatal canine impactions made the experimental group $(n=34)$, while the patients who were being referred to the same department but without palatal canine impactions made the control group $(\mathrm{n}=71)$. The sellae were drawn from the lateral cephalometric radiographs, while the palatal canines were checked on the OPG. The inclusion criterion for the study was firstly, age above 12 years so that the development was complete and secondly, superior quality lateral cephalometric radiographs and OPGs. The exclusion criteria would be patients having severe craniofacial deformities requiring a combined orthodontic surgical treatment, any syndromes, or history of facial traumas.
Lateral cephalometric radiographs of the experimental and control group were taken and sella turcica was traced. The outline of the sella was drawn from the top of tuberculum sellae to dorsum sellae, in a darkened room on acetate sheet using a lead pencil, by one researcher (Figure 1). The sella length (distance from dorsum sella to the tuberculum sella), the greatest anteroposterior diameter (from tuberculum sella to the greatest distance in the inner wall of the sella) as well as sella depth (a perpendicular from the line above to the deepest point on the floor of sella) was drawn (Figure 2). This length measurement was a representative of the ICL (interclinoidal ligament) calcification as taken by Leonardi. ${ }^{8}$

On the basis of sellar dimensions, the bridging was classified into 3 groups.

1. No calcification: It is called type I, when the length is either equal or greater than three fourths of the diameter. 2. Partial calcification: It is called type II, when the length is equal or less than three fourths of the diameter. 3. Complete calcification: It is called type III, when only the diaphragm sellae can be seen on the radiograph.

A single researcher traced the Sellae of all the cases while the rest of the form and confirmation of presence or absence of other dental anomalies were done by a second researcher later to reduce the bias.

To reduce the intra examiner bias, 10 radiographs were randomly selected and re-traced by the first researcher to find any significant variations with the earlier tracings after a week. The value of kappa coefficient was 0.81 showing strong strength of agreement.

\section{STATISTICAL ANALYSIS}

SPSS version 17 was used to perform the statistical analysis of the data. The level of significance was set as 0.05 . The independent sample $t$ test compared the sella dimensions among experimental subjects and controls. Chi-square test was used to evaluate the association between interclinoidal calcification among subjects and control. Pearson correlation test was used to estimate the strength of association between impacted canines and sella bridging.

\section{RESULTS}

The independent sample $t$ test revealed a significantly reduced mean interclinoidal distance $(\mathrm{p}=.007)$ and sella diameter $(\mathrm{p}=.0001)$ among subjects with impacted canine. However, no significant difference was seen in mean sella depths between both groups (Table 1). Among subjects, when both genders were compared no significant difference in sella dimensions was found (Table 2).

In the experimental group, 26 (76.5\%) participants were 
Table 1: Comparison of sella dimensions ( $\mathrm{mm}$ ) among experimental subjects and controls

\begin{tabular}{|c|c|c|c|}
\hline STUDY GROUP & \multicolumn{3}{|c|}{ SELLA DIMENSIONS } \\
\hline & $\begin{array}{c}\text { Sagittal Interclinoidal } \\
\text { Distance }\end{array}$ & Sella Depth & Sella Diameter \\
\hline Subjects $(\mathrm{n}=34)$ & $3.4 \pm 1.6$ & $6.6 \pm 1.1$ & $6.4 \pm 1.1$ \\
\hline Controls $(\mathrm{n}=71)$ & $4.4 \pm 1.6$ & $7.1 \pm 1.2$ & $7.8 \pm 1.4$ \\
\hline P-value & .007 & 0.05 & .0001 \\
\hline
\end{tabular}

Independent sample t test

Table 2: Sella turcica measurements $(\mathrm{mm})$ in experimental subjects stratified by gender.

\begin{tabular}{|l|l|l|l|}
\hline Sella measurements & Male(n=18) & Female(n=16) & P value \\
\hline $\begin{array}{l}\text { Sagittal Interclinoidal } \\
\text { distance }\end{array}$ & $3.8 \pm 1.7$ & $2.9 \pm 1.4$ & 0.1 \\
\hline Sella Depth & $6.6 \pm 1.1$ & $6.6 \pm 1.1$ & 0.9 \\
\hline Sella Diameter & $6.6 \pm 1.3$ & $6.2 \pm 0.9$ & 0.3 \\
\hline
\end{tabular}

Independent sample $\mathrm{t}$ test

Table 3: Degree of calcification in experimental subjects and controls

\begin{tabular}{|c|c|c|c|c|}
\hline \multirow[t]{2}{*}{ Study Group } & \multicolumn{4}{|c|}{ Sella Bridging, $n(\%)$} \\
\hline & Type 1 & Type 2 & Type 3 & $P$ value \\
\hline Subjects $(n=34)$ & $7(20.6)$ & $26(76.5)$ & $1(2.9)$ & 0.96 \\
\hline Controls $(n=71)$ & $13(18.3)$ & $56(78.9)$ & $2(2.8)$ & \\
\hline
\end{tabular}

Chi Square

Table 4: Sella bridging in the experimental subjects

\begin{tabular}{|l|l|l|l|}
\hline Sella Bridging & Males( $\mathbf{n = 1 8 )}$ & Females $(\mathbf{n}=\mathbf{1 6})$ & \multirow{2}{*}{ P value } \\
\hline Type 1 & 5 & 2 & \\
\hline Type2 & 13 & 13 & \\
\hline Type 3 & 0 & 1 & \\
\hline
\end{tabular}

Chi Square

Table 5: Strength of association among subjects and controls

\begin{tabular}{|l|l|l|}
\hline & P value & Pearson Correlation \\
\hline Subjects & 0.0001 & -0.80 \\
\hline Controls & 0.0001 & -0.64 \\
\hline
\end{tabular}

Mean age control: $19.7+3.4$

Mean age experimental group: $17.2+4.1$

identified with type 2 calcification. Similarly, in controls 56 (78.9\%) participants were identified with type II calcification of sella ligament. Chi-square test reveals no significant difference in degree of calcification among both groups (p 0.960) Table 3.

There was also no significant difference in degree of sella bridging when both genders of the experimental group were compared Table 4 . The strength of association between impacted canines and sella bridging was estimated using Pearson correlation test. The significant negative correlation was found among subjects and controls. However, the strength of association is higher among experimental subjects as compared to control group.

\section{DISCUSSION}

Impacted canines are a clinical anomaly encountered very often by practicing orthodontists. Assessment of the canine being palatally or buccally impacted is clinically difficult and usually requires a parallax technique. There are however, some genetic manifestations that can aid in positional assessment of the impaction. Conditions that point towards buccal impactions include arch crowding and decreased maxillary arch width while agenesis of third molars and maxillary lateral incisors and infraoccluded deciduous teeth are conditions pointing towards palatal impactions. The connection between sella bridging and palatal canine impactions has been the subject of interest of many researchers lately as lateral cephalograms are a routine aid taken before commencing orthodontic treatment and sparse information is available on this subject locally as well as internationally.

Sella bridge is formed by exaggerated ossification between anterior as well as posterior clinoid processes of sphenoid bone. ${ }^{7}$ The incidence of sella bridging has been found to be between 1.1 to $13 \%$ in healthy individuals. ${ }^{7,9}$ The $\mathrm{S}$ point which is the geometric centre of sella turcica forms the SN line with Nasion point and has a major contribution in cephalometric readings. ${ }^{9}$

Sella turcica can be easily seen and measured on a lateral cephalogram, an $\mathrm{x}$-ray that is done routinely for comprehensive orthodontic treatment. Morphologically, sella turcica has different shapes as given in the study of Nagaraj et al. ${ }^{10}$ The shapes include:

- Normal Sella Turcica

- Oblique anterior wall of sella

- Bridging of sella

- Sella with double contoured floor

- Irregular shape of dorsum sella

- Pyramidal shaped sella

Becktor et $\mathrm{a}^{11}$ classified sella bridging into two groups:

- Type A: ribbon-like fusion.

- Type B: extension of the anterior and/or the posterior clinoid process.

According to our study, interclinoidal distance as well as sella diameter was reduced in patients with impacted canines while sella depth showed no difference in controls and subjects (Table 1). Our results partially agree with those of Scribante et al, ${ }^{9}$ in which only the interclinoidal distance was decreased in subjects with dental anomalies while depth 
and diameter remained same amongst controls and subjects. ${ }^{10}$ In a study By $\mathrm{Ali},{ }^{7}$ the interclinoidal distance was reduced, but depth and diameter showed no differences. Najim and Nakib $^{12}$ in their study also showed that sella length was decreased in subjects with impacted canines but depth and diameter remained insignificant. Jones et al, ${ }^{13}$ in their study observed that patients who were treated either by surgicalorthodontics or orthodontics only showed sella dimensions in which only interclinoidal distances were reduced compared to depth and diameter.

In our study, no significant differences in sella dimensions were seen in experimental subjects during gender comparison (Table 2). Our study is in accordance with the study of Ali, ${ }^{7}$ who also did not observe any difference in sella dimensions in both males and females. In a study by Sami and Ahmed, ${ }^{14}$ interclinoidal ossification and length of sella were not influenced by age and gender. In a study by Konwar, ${ }^{15}$ linear dimensions including length, diameter as well as depth did not show significant differences between genders. Najim and Nakib in their study reported that no statistically significant difference was noted in linear sellar measurements when gender was compared.12 Francis et al found contrasting results in their study as they found larger sellae in female subjects. They concluded that race and ethnicity might be significant factors leading to this difference. Also Boddeti et al in their study found linear sella measurements to be larger in males and in larger age group while it was smaller in females and young age group.

Our study showed increased frequency of sella bridging in experimental subjects. Partial calcification was found in $76 \%$ cases while complete calcification was found in $3 \%$ cases and the combined percentage of partial and complete calcification was nearly $80 \%$ (Table 3 ). In the study of Najim and $\mathrm{Nakib}^{12}$, the combined result of partial and complete ossification surmounted to $70 \%$. The study of Ali showed the combined percentage to be $80.6 \%$ and is comparable to our study. The incidence of sella turcica bridging in a study by Ghadimi ${ }^{18}$ showed a prevalence of $60 \%$ in patients with impacted canines.

In our study, the control group showed an increased frequency of type 2 calcifications which was found to be $78.9 \%$ (Table 3 ). These readings are comparable to those of the subjects $(76.5 \%)$ of our study (Table 3$)$. This finding is in accordance with the study of Ali, ${ }^{7}$ who showed nearly the same percentage of controls and subjects with type 2 calcification.

Thus, a relation exists between sella bridging and palatally impacted canines as established in our study (Table 5) and through the review of literature of various other researches. This relation has an important clinical significance in diagnosing palatally impacted canines in children undergoing orthodontic treatment. Various interceptive methods to resolve palatal canine impactions are available if done at the right point of time. These include rapid maxillary expansion, extraction of deciduous canine, extraction of deciduous canine and first deciduous molar as well as placement of cervical pull headgear used alone or in combination with extraction of deciduous canine. ${ }^{19}$

\section{CONCLUSION}

From our study, we were able to conclude that Interclinoidal calcification/ sella bridging is an indicator of palatally canine impaction. Sella lengths as well as diameter were reduced in subjects with palatal impacted canines. Type II calcification was the dominant type found in both subjects and controls. The prevalence is common in both males and females.

\section{ACKNOWLEDGEMENTS}

There was no financial support to this study neither it had any commercial interests.

\section{CONFLICT OF INTEREST}

None declared.

\section{REFERENCES}

1. Baccetti T. A controlled study of associated dental anomalies. Angle Orthod 1998;68(3):267-74.

2. Bishara SE, Athanasiou AE. Cephalometric methods for assessment of dentofacial changes. In: Athanasiou AE, editor. Orthodontic Cephalometry. London, United Kingdom: Mosby-Wolfe; 1995.

3. Sathyanarayana HP, Kailasam V, Citharanjan AB. Sella turcica-its importance in orthodontics and craniofacial morphology. Dent Res J (Isfahan). 2013;10(5): 571-75

4. Leonardi R, Barbato E, Vichi M, Caltabiano M. A sella turcica bridge in subjects with dental anomalies. Eur J Orthod. 2006 ;28(6):580-85

5. Axelsson S, Storhaug K, Kjaer I. Post-natal size and morphology of the sella turcica. Longitudinal cephalometric standards for Norwegians between 6 and 21 years of age.Eur J Orthod. 2004; 26(6):597-604.

6. Perez EI, Chavez K A \& Ponce D. Frequency of sella turcica bridge and clinoid enlargement in lateral cephalometric plain film radiography from Peruvians. Int J Morphol, 2013;31(2):373-77

7. Ali B, Shaikh A, Fida M. Association between sella turcica bridging and palatal canine impaction. Am J Orthod Dentofacial Orthop 2014;146:437-41 2014;146:437-41 
8. Leonardi R, Farella M, Cobourne MT. An association between sella turcica bridging and dental transpositions. Eur J Orthod. 2011;33:461-65

9. cribante A, Sfondrini MF, Cassani M, Fraticelli D, BeccariI S and Gandini P. Sella turcica bridging and dental anomalies: is there an association? Int J of Paediatr Dent 2017;27:568-73

10. Nagaraj T, Shruthi R, James L, Keerthi I, Balraj L, Goswami RD. The size and morphology of sella turcica: A lateral cephalometric study. J Med Radiol Pathol Surg 2015;1:3-7.

11. Becktor JP, Einersen S, Kjaer I. A sella turcica bridge in subjects with severe craniofacial deviations. Eur J Orthod 2000; 22: 69-74

12. Najim AA, Nakib LA. A cephalometric study of sella turcica size and morphology among young Iraqi normal population in comparison to patients with maxillary malposed canine. J Baghdad Coll Dent 2011;23:53-8.

13. Jones RM, Faqir A, Millett DT, Moos KF, McHugh S. Bridging and dimensions of sella turcica in subjects treated by surgical orthodontic means or orthodontics only. Angle Orthod 2005;75:714-18.

14. Sami Q, Ahmed I. Association between sella turcica bridging and buccal and palatal canine impaction. Asian Acad Res J Multidiscip 2016;3(6):.
15. Konwar SK, Singhla A, Bayan R. 2016. Morphological (Length, Depth, and Diameter) Study of Sella Turcica in Different Mandibular Growth Patterns in Indians. Int J Dent Med Spec. 2016;3(3):4-9.

16. Francis CC. Growth of the human pituitary fossa. Hum Biol. 1948;20:1-20.

17. Boddeti SS, Varma NS, Sasidhar YN, Ujwala T, Navya P. The Size and the Morphology of Sella Turcica in Different Skeletal Patterns of South Indians: A Lateral Cephalogrametric Study. Int J Oral Health Med Res. 2016;3(1):13-16.

18 Ghadimi MH, Amini F, Hamedi S, Rakhshanc V. Associations among sella turcica bridging, atlas arcuate foramen (ponticulus posticus) development, atlas posterior arch deficiency, and the occurrence of palatally displaced canine impaction. Am J Orthod Dentofacial Orthop 2017;151:513-20.

https://doi.org/10.1016/j.ajodo.2016.08.024

19. Baccetti T. Risk Indicators and Interceptive Treatment Alternatives for Palatally Displaced Canines. Semin Orthod 2010;16:186-192. https://doi.org/10.1053/j.sodo.2010.05.004 